\title{
Traditional arts and crafts: Responsible lifestyle products' design through heat transfer printing
}

\author{
LaimayumJogeeta Devi ${ }^{1}$, Anita Rani ${ }^{2}$, Manisha Gahlot ${ }^{3}$ and Vandana Bhandari ${ }^{4}$
}

${ }^{1}$ Ph. D. Research Scholar, Department of Apparel and Textile Science, College of Community Science, Punjab Agricultural University, Ludhiana, Punjab, India

2\&3Professor, Department of Clothing and Textiles, College of Home Science, GBPUA\&T, Pantnagar, Uttarakhand, India ${ }^{4} \mathrm{Ph}$. D. Research Scholar, Department of Textile and Apparel Designing, IC College of Home Science, CCSHAU,

Hisar, Haryana, India

\section{To Cite this Article}

LaimayumJogeeta Devi, Anita Rani, Manisha Gahlot and Vandana Bhandari, "Traditional arts and crafts: Responsible lifestyle products' design through heat transfer printingmy", International Journal for Modern Trends in Science and Technology, 6(9S): 234-241, 2020.

\section{Article Info}

Received on 25-August-2020, Revised on 08-September-2020, Accepted on 12-September-2020, Published on 18-September-2020.

\section{ABSTRACT}

Sustainability is the key to responsible production and conservation of environment, which is the need of the hour. Indian motifs based on traditional textile arts and crafts have always been a source of inspiration not only to Indian designers but also have intrigued global designers. These motifs can be adapted into lifestyle products through modern techniques of surface enrichment. Lifestyle products hold a lucrative market in the textile sector. Apron is one such lifestyle product which falls under the category of accessories. This study explores how traditional knowledge of Indian arts and crafts can open up avenues for responsible designing of lifestyle products. In the present study, fifty motifs/designs from textile and architectural sources of Manipur were collected from secondary sources, adapted and simplified for application in kitchen apron using CorelDraw X3 software. Ten adapted designs were selected through visual inspection by a panel of thirty judges. The design arrangements were developed for kitchen apron by preparing line patterns, motifs/designs layout and colourways, respectively. The outcome of every step was visually evaluated by the same panel of thirty judges, except for the line patterns, on five point scale. The prototype scoring highest weighted mean score i.e., rank I was selected for further developing the following consequent steps. The finalized designs were printed on the paper using disperse dyes. The printed papers were then used to transfer designs on the constructed and finished apron made of polyester/cotton blended fabric. The cost of apron was estimated Rs. 244/- which can be reduced if produced in bulk. Consumer assessment was carried out for the printed apron on various aesthetic parameters. Consumers' acceptance for the printed apron was found high which reflected its marketability owing to uniqueness of the motifs, traditional values associated with the traditional motifs of Manipur, sharpness of design lines, the clarity of prints and the reasonable price. Thus, study outcome revealed that the designs inspired from traditional textile arts and crafts of Manipur can be successfully rejuvenated into lifestyle products through heat transfer printing which is environmentally feasible, socially acceptable and economically viable.

KEYWORDS: Motifs/designs, design adaptation, lifestyle products, heat transfer printing and sustainability 


\section{INTRODUCTION}

Sustainability is the key to responsible production and conservation of environment, which is the need of the hour. However, garment making process are still not considered to be ethically and ecologically sustainable due to various factors. This study explores how Indian crafts can open up avenues for responsible designing of lifestyle products. Indian motifs based on traditional textile arts and crafts has always been a source of inspiration not only to Indian designers but also have intrigued global designers. Application of technical skills of Indian artisans to the contemporary designs enables opportunities to enter the global market. These motifs can be adapted into lifestyle products through modern techniques of surface enrichment. Heat transfer printing is one such technique where complicated designs can be printed with sharp lines and full detailing. Wet processing and after washing is not required in heat transfer printing hence, no release of effluents.

Lifestyle products holds a lucrative market in the textile sector. Apron is one such lifestyle product which falls under the category of accessories. Today's highly competitive fashion market constantly needs to 'refresh' product ranges. This has led to the appearance of small collections of merchandise developed on the idea of 'Here Today, Gone Tomorrow' to suit to the demands of the consumers. Consumers prefer more of the utility products that reflect their lifestyle effectively. Heat transfer printing is ideal for small scale production and customization. So, contemporary products offered with private labels by designers work out the best with the changing demands of modern market and consumers' inclination towards traditional values [10]. In light of these statements, the present study was planned which aimed at responsible designing of lifestyle products using motifs/designs from traditional textile and architectural crafts of Manipur in an affordable price range.

\section{REVIEW OF LITERATURE}

Textile printing is the process of applying colour to fabric in definite patterns or designs. The colour is bonded with the fibre to resist loss in washing and friction [6]. Transfer printing was introduced in 1960 by utilizing basic chemical principle whereby substances can be made to pass from a solid state directly to a vapour state when heated and returns directly to solid state when cooled. It is the process by which heat-applied materials containing a heat-sensitive adhesive are applied to textiles with the help of heat press. When heat is applied by a heat press to the layer of heat-applied material and the substrate, the material adheres to the substrate to which it is being applied there by resulting a decorated garment [2].

The transfer of colours takes place as the colour sublimes through vapourization. Printing is carried out by pressing the paper on the fabric at high temperature at $424^{\circ} \mathrm{F}$ or $200^{\circ} \mathrm{C}$. It is most effective on nylons and polyesters but can also be used on acrylics, triacetates and polyester cotton blend with high polyester percentage. Cellulosic fabrics treated with synthetic resins that accept disperse dyes can be heat transfer printed. Advantages of heat transfer printing over other printing methods includes sharpness and clarity of designs, simple operation, low processing cost, few manpower requirement, possibility of rapid change of designs by simply changing the design paper, successful application on knitted fabrics, possibility of multicolour prints, less chances of loss of fabric through faulty printing, low energy requirements, possibility to print the garment in pieces and possibility of the precise placement of a decorative motifs on completed garments [23].

Studies on various Indian arts and crafts, their documentation, revival and adaptation to contemporary products have been conducted by different researchers. Phulkari embroidered traditional and contemporary articles were documented and studied the historical aspects and its modifications [16]. It has been reported that Phulkari embroidered articles were increased in numbers but the quality of work was compromised [16]. Traditional folk art of Punjabi phulkari has regained its popularity through commercialization but the quality and durability was found to be deteriorated with the commercial intervention for monetary returns instead of conservation. However, the ongoing revival work of phulkari by NGOs helped rural poor by providing jobs to women [15]. Innovative and creative fashion accessories like bags, belt, stoles and neckties inspired from the hand woven textiles and ornaments ofChaketsang, Ao and Lotha tribes of Nagaland have been successfully designed which helped to uplift, preserve and popularize the hand woven textiles of the state through product diversification [14]. Researchers have already 
worked on adaptation of aipan designs [13, 21, 5, 19], kalamkaridesign [12] and warlipaintings [24] for application on various textile based products using different techniques of block printing, weaving technique of Meghalaya, tie and dye, applique, heat transfer printing and block printing respectively. Traditional designs of Manipur have been studied for adaptation on kurti [11], saree andsalwar-kameez [8, 9] through heat transfer printing [11], stencil and hand block printing $[8,9]$, respectively. Motifs of aipan folk art have also been adapted on various articles, respectively [7, 20,3].

Appliqué saris embellished with hand, machine and digital embroidery were successfully developed using selected traditional motifs developed through CAD software into contemporary forms and designs which proved that traditional motifs can be created into contemporary forms [22]. A case study conducted on 'Deshi Dosh', a group of Bangladeshi fashion houses which focused on culture and tradition in the centre of fashion offering unique product features and exclusive product range, operating under a unified corporate identity explored the competitive advantage achieved in the context of developing country [1]. It was also reported in a study that the emerging Australian designers and traditional artisans in India could foster new possibilities for ethically sustainable collaborations between Australia and India. Industry connection between Indian textile artisans should be encouraged to apply their traditional technical skills to contemporary design, thus enabling new opportunities to enter the global market [18].

Hence the efforts of promoting traditional crafts for contemporization through collaboration will offerresponsible product designs that is the need of the hour for environmental conservation and sustainable development.

\section{MATERIALS AND METHODS}

Designs/motifs from textile andarchitectural origin of Manipur were collected from secondary sources $[17,4]$. In the present study, fifty motifs/designs were collected, twenty-five each from textile and architectural sources of Manipur. The collected designs/motifs were then adapted, smoothened out and simplified to make them suitable for application in the lifestyle product i.e., kitchen apron by hand sketching. Design/motifs were selected through visual inspection by a panel of thirty judges from the Department of Clothing and Textiles, College of Home Science, GBPUA\&T, Pantnagar, on the basis of suitability of the adapted motifs for printing technique, reflection of Manipuri culture and overall appeal of the motifs on five point scale. The design arrangements were developed for kitchen apron by preparing line patterns, motifs/designs layout and colourways, respectively using CorelDraw X3 software. The outcome of every step was visually evaluated by the same panel of thirty judges, except for line patterns, throughout the entire research and the prototype scoring the highest weighted mean score i.e., rank I was selected for further development. Five possible line patterns were developed irrespective of the actual motifs to be printed on apron. One line pattern was selected on the basis of visual evaluation by a panel of fifteen experts from the Department of Clothing and Textiles, College of Home Science, GBPUA\&T, Pantnagar, by assigning order of preferences on the basis of suitability of the line pattern to apron. Line pattern with the highest weighted mean score and rank I was selected. Design combinations using single motifs, two motifs and three motifs were prepared on the basis of their compatibility to make a design and suitability of designs for placement in the selected line pattern. Five motifs/designs layouts were prepared for apron by placing the design combinations on the selected line pattern. One motifs/designs layout was selected which had the highest weighted mean score and rank I through visual evaluation by the same panel of thirty judges. Three colourways were developed using three colour schemes viz., analogous, complementary and split complementary on the selected motifs/designs layout. Spring/summer 2016 Pantone $^{\circledR}$ colour planner report was used instead of traditional colours used in textile and architectural designs of Manipur. Colourway scoring the highest weighted mean score and rank I, through the assessment by the same panel of thirty members on the basis of the aesthetic appeal of the design layout was selected as the final design for apron to be printed on papers.

The finalized designs were printed on transfer paper using disperse dye sublimation ink at Aradhya Prints, PeeraGarhi, Delhi. Raw materials like polyester/cotton blended fabric with higher polyester content, threads and trims were procured from the local retail stores of Pantnagar and Rudrapur. Designs were then transferred from the printed papers on the constructed and finished 
apron made of polyester/cotton blend by applying heat and pressure for 25 seconds at $215^{\circ} \mathrm{C}$ temperature and 120 psi pressure in Dyeing and Printing Lab, Dept. of Clothing and Textiles, GBPUA\&T, Pantnagar. Cost of the printed apron was calculated, considering the parameters, viz., fabric cost, stitching charges, printing cost (labour and electricity) and $5 \%$ overhead charge of the total cost. Finally, the consumer acceptability of the printed lifestyle product i.e., apron was assessed. The respondents were thirty female M. Sc. students selected through stratified random sampling technique from the College of Agriculture, College of Home Science and the College of Technology, GBPUA\&T, Pantnagar.

\section{RESULTS AND DISCUSSION}

Traditional motifs/designs used in the traditional textile of Manipur were found to be mostly derived from nature like flora and fauna, which are stylized, realistic, abstract and geometrical. Lamthangkhut-hat, lindumayek, khoimayek, sangai, kundo, leihao, etc. were somecommon traditional textile motifs of Manipur while commonly used motifs in tribal architecture of Manipur included human head, buffalo head, moon, sun, tiger, etc. which reflected their mindset in order to express facets of hard life and perception of beauty and grace. In the present study, ten adapted motifs/designs were selected, five each from textile and architectural origin, which scored the highest weighted mean scores and ranks I to $\mathrm{V}$ through visual evaluation by a panel of thirty judges from the Department of Clothing and Textiles, College of Home Science, GBPUA\&T, Pantnagar, on five point scale for use in design arrangement and layout.The selected adapted motifs were shamayek, khoiakoibi mayek-1, khamenchatpamayek, khoiakoibi mayek-2 and ngamayekfrom textile origin andhuman figure-1, deer, tiger, human figure-2 and buffalo head from architectural origin which is given in Plate 1.

Apron got weighted mean score 4.0 and rank I. Hence it was selected by the same panel of thirty members from four lifestyle products of utility accessories viz., apron, mitton, slip on sun protector/face cover and pot holder, on the basis of order of preference for these products according to their ability to highlight the lifestyle of the user. The details are given in Table 1 .
Out of the five line patterns prepared for apron, the pattern which scored the highest weighted mean score 4.33 and rank I, was selected by a panel of fifteen experts on the basis of its suitability to the utility lifestyle product i.e., apron. The selected line pattern is given in Plate 2 .

Five different design combinations comprising of single motif, two motifs and three motifs, were prepared using the ten selected adapted motifs on the basis of aesthetics and compatibility among the motifs as well as to the garment. Five design layouts were developed by using these design combinations in the selected line pattern. Same panel of thirty members

Plate 1 Selected adapted motifs

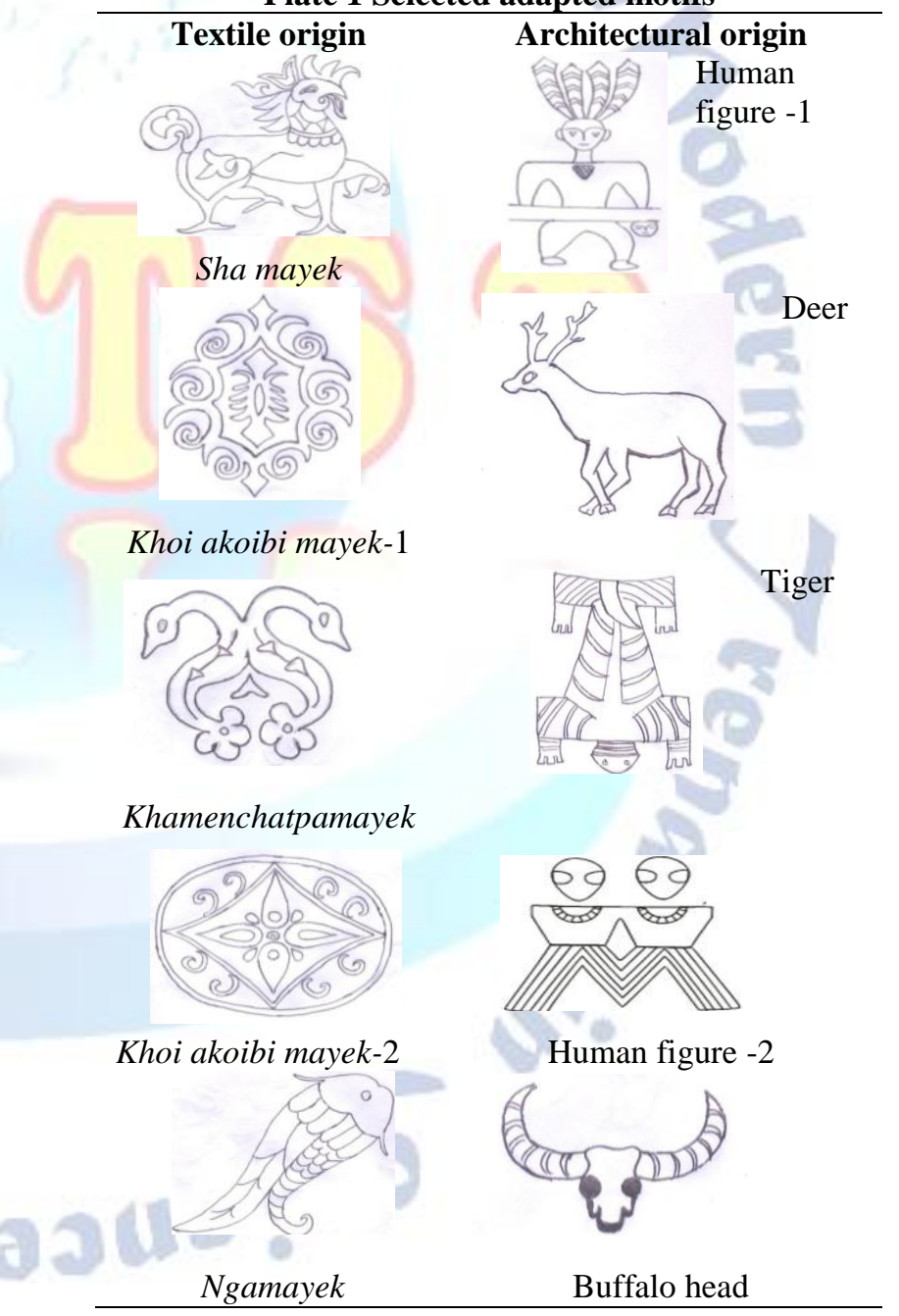


Table 1 Preference for lifestyle products of utilitv accessories

\begin{tabular}{|c|l|c|c|}
\hline $\begin{array}{l}\text { Sl. } \\
\text { No. }\end{array}$ & Accessories & $\begin{array}{c}\text { Weighted } \\
\text { Mean Score }\end{array}$ & Rank \\
\hline 1 & *Apron & 4.00 & I \\
\hline 2 & Mitton & 3.00 & II \\
\hline 3 & $\begin{array}{l}\text { Slip on sun } \\
\text { protector/ face } \\
\text { cover }\end{array}$ & 2.00 & III \\
\hline 4 & Pot holder & 1.03 & IV \\
\hline \multicolumn{2}{|c|}{ Average } & \multicolumn{2}{|c|}{2.50} \\
\hline
\end{tabular}

evaluated the design layouts visually on the basis of overall aesthetic appeal and the layout with the highest weighted mean score, 3.33 and rank I was selected. The selected design layout was made of three design combination i.e., khoi akoibi-1, khoi akoibi-2 and deer motif, which is given in Plate 2 . Out of the three colour schemes applied to the design layout, analogous colour scheme using yellow, yellow-green and green coloursalong with a neutral colourwas selected which got highest weighted mean score with 2.53 and rank I, through visual evaluation by the same panel of thirty experts on the basis of overall appearance of the design as well as the lifestyle product, i.e., apron. The selected colourway is given in Plate 2 .

Developed design arrangement was printed on the paper and then used to transfer on the constructed apron as shown in Fig 1. The cost of apron was calculated on the basis of fabric cost, cost of printing designs on paper, stitching charge, labour cost, electricity charge and $5 \%$ overhead charge against the printing of lifestyle product i.e., apron. The cost of the printed apron was Rs. 244/as shown in Table 2, which can be reduced if produced in bulk. The calculated cost is simply the cost without profit margins, thus, selling price of the printed lifestyle product i.e., apron can be calculated by adding appropriate profit margins to the cost price.

Consumer assessment was carried out for the printed apron on five aesthetic parameters by thirty respondents selected through stratified random sampling technique from female post graduate students of GBPUA\&T, Pantnagar on five aesthetic parameters viz., combination of motifs in the arrangement, suitability of colour combination used in design arrangements, uniqueness of designs and design arrangements, printing quality and overall appearance. It is clear from Table 3 that $40 \%$ of the consumers ratedcombination of motifs in the arrangement as excellent, $50 \%$ rated uniqueness of designs and design arrangements and overall appearance as very good, $46.66 \%$ rated suitability of colour combination used in the design arrangement as good. Only $2 \%$ of the consumers rated poor in printing quality.

Plate 2 Design layouts

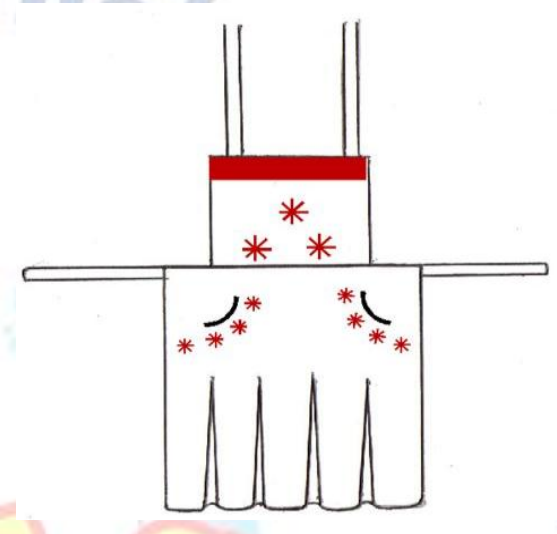

Selected Line Pattern

(Weighted mean score $=4.33$, rank $=I)$

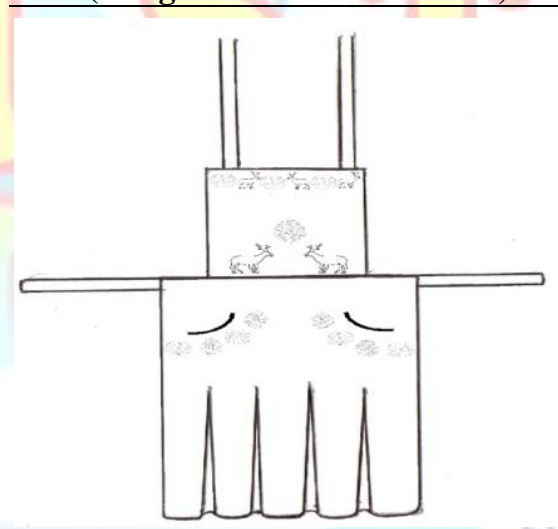

Selected design layout (Weighted mean score $=3.33$, rank=I)

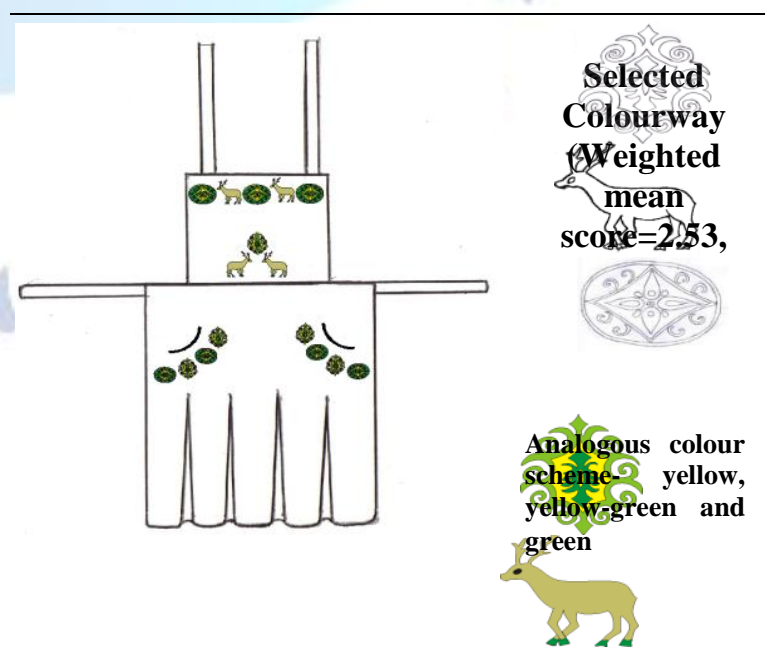




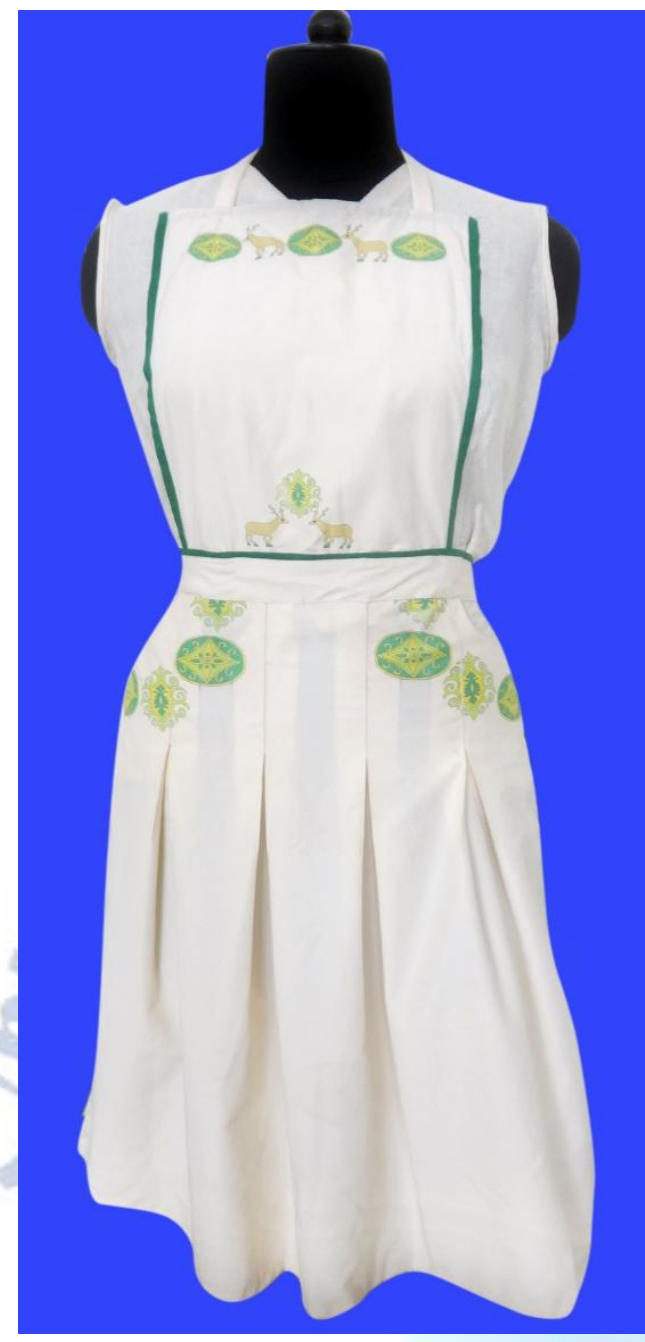

Table 2 Cost of printed apron

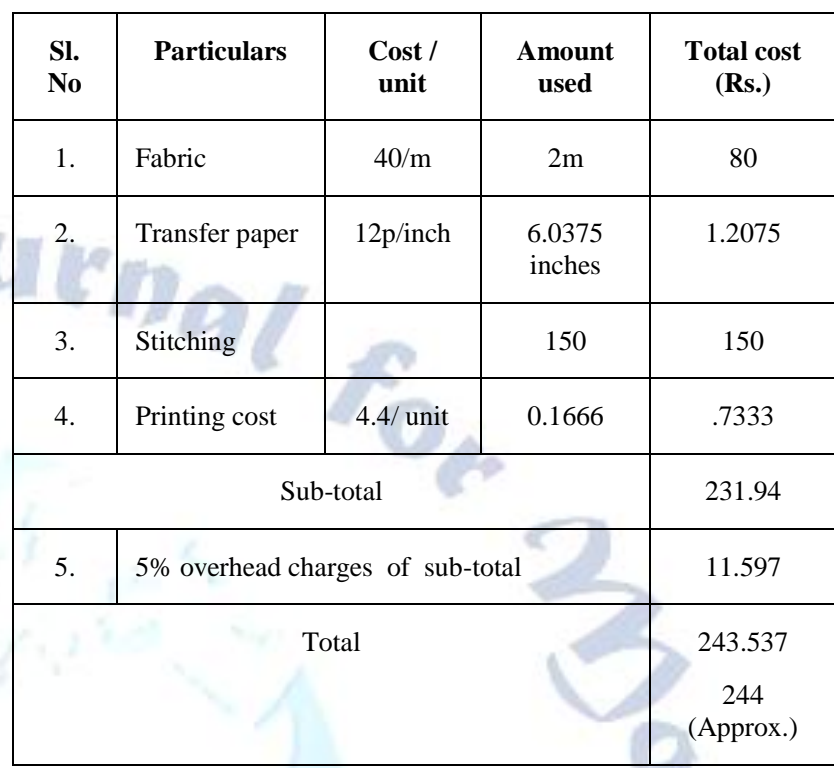

Fig 1 Printed apron

Table 3 Consumers' preferences for apron on aesthetic parameters

\begin{tabular}{|c|c|c|c|c|c|c|c|c|c|}
\hline \multirow{2}{*}{$\begin{array}{l}\text { Sl. } \\
\text { No. }\end{array}$} & \multirow{2}{*}{ Parameters } & \multicolumn{5}{|c|}{ Level of acceptability } & \multirow{2}{*}{$\begin{array}{l}\text { Total } \\
\text { scores }\end{array}$} & \multirow{2}{*}{ WMS } & \multirow{2}{*}{ Ranks } \\
\hline & & Excellent & Very good & Good & Fair & Poor & & & \\
\hline 1. & $\begin{array}{l}\text { *Combination of motifs in } \\
\text { the arrangement }\end{array}$ & $\begin{array}{c}12 \\
(40)\end{array}$ & $\begin{array}{c}10 \\
(33.33)\end{array}$ & $\begin{array}{c}8 \\
(26.66) \\
\end{array}$ & - & - & 127 & 4.23 & I \\
\hline 2. & $\begin{array}{l}\text { Suitability of colour } \\
\text { combination used in design } \\
\text { arrangements }\end{array}$ & $\begin{array}{c}7 \\
(23.33)\end{array}$ & $\begin{array}{c}9 \\
(30)\end{array}$ & $\begin{array}{c}14 \\
(46.66)\end{array}$ & - & - & 113 & 3.7 & V \\
\hline 3. & $\begin{array}{l}\text { Uniqueness of designs and } \\
\text { design arrangements }\end{array}$ & $\begin{array}{c}11 \\
(36.66)\end{array}$ & $\begin{array}{c}15 \\
(50)\end{array}$ & $\begin{array}{c}3 \\
(10) \\
\end{array}$ & $\begin{array}{c}1 \\
(3.33) \\
\end{array}$ & - & 126 & 4.2 & II \\
\hline 4. & Printing quality & $\begin{array}{c}11 \\
(36.66)\end{array}$ & $\begin{array}{c}12 \\
(40)\end{array}$ & $\begin{array}{c}4 \\
(13.33)\end{array}$ & $\begin{array}{c}1 \\
(3.33)\end{array}$ & $\begin{array}{c}2 \\
(6.66)\end{array}$ & 119 & 3.96 & III \\
\hline 5. & Overall appearance & $\begin{array}{c}8 \\
(26.66) \\
\end{array}$ & $\begin{array}{c}15 \\
(\mathbf{5 0})\end{array}$ & $\begin{array}{c}5 \\
(16.66) \\
\end{array}$ & $\begin{array}{c}2 \\
(6.66)\end{array}$ & 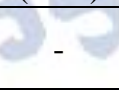 & 119 & 3.96 & III \\
\hline
\end{tabular}

*Most preferred parameters

** Values in parenthesis indicate percentage

\section{CONCLUSION}

Consumers' acceptance for the printed apron was found high which reflected its marketability owing to uniqueness of the motifs, traditional values associated with the traditional motifs of Manipur, sharpness of design lines, the clarity of prints and the reasonable price. The study was an attempt to design and diversify the motifs/designs from the traditional textile and architectural crafts of Manipur through application on lifestyle products. Lifestyle products were responsibly designed taking into consideration the sustainability aspects 
and affordability. Heat transfer printing is sustainable and environmentally friendly as it is waterless technique of printing which does not release effluents. Sharp outlines, clarity of prints, simple and inexpensive printing equipment,less floor space requirement, easy operation, low consumption of time,no after washing required, makes heat transfer printing a pollution free processing, cost effective for producing small lots, low energy requirements which is successful in printing both woven and knitted fabrics. The study showed that not only the traditional textile motifs/designs but also architectural designs of Manipur can be a great source of design inspiration having a very promising potential to occupy a niche in the fashion market both at national as well as global levels owing to its distinctiveness and uniqueness. Such types of products would offer modern consumer, the originality and would also bring aspects of Manipuri culture, through designs on textiles, in the mainstream Indian market. The use of designs derived from traditional crafts of Manipur would also be a step towards expanding the design base of India.

The result of this research is in line with the previous studies conducted by Jangwan (2009), Devi and Srivastava (2013) and Devi et al. (2019)on heat transfer printing of kurtis using Kalamkari design; adaptation of Manipuri designs on salwar-kameez through stencil and block printing and designing of kurti using traditional designs of Manipur through transfer printing, respectively with high acceptability and appreciation of the final products by the potent consumers with good market potential $[12,8,11]$. The study is also supported by a study conducted by Lantry (2015), which emphasized on building an economically sustainable and ethical practice considering contemporary design in fashion and textiles [18].

This study explored how traditional knowledge of Indian arts and crafts can open up avenues for responsible designing of lifestyle products. Amalgamation of traditional technical skills to contemporary design provides new opportunities to enter the global market.The outcomes of the present study can be utilized further for application on textiles through variety of surface enrichment techniques like embroidery, screen printing, block printing or painting by local artisans, researchers or designers for creating the products that could fulfill needs of niche market and help in generating income and empowering themselves but keeping the quality and traditional values intact in a sustainable way. Thus, the study revealed that the designs inspired from traditional textile arts and architectural crafts of Manipur can be successfully rejuvenated into lifestyle products through heat transfer printing which is environmentally feasible, socially acceptable and economically viable.

\section{REFERENCES}

1. U. Ahmed,A. Rifat, ,N. Nisha, and M.J. Uddin (2015). Deshi Dosh: the case on integration of ten rivals in the fashion industry of Bangladesh. Decision. 42(1): 87-103.

2. Arts and architecture.http://www.webindia123.com/ MANIPUR/ART/ index, last accessed on 2016/5/24

3. A. Arya, M.Gahlot, and A. Rani (2017) Adaptation of aipan designs (A floor art of Uttarakhand) for designing of saree. Inter $J$ of App Res. 3(7):737-743.

4. M. Bahadur and Y. Shantabai (1996) Tribal art of Manipur. $2^{\text {nd }}$ ed. Imphal, Mutua Museum. p vii, 1.

5. R.Bala(2012) Textile designing through tie and dye technique using Aipan design of Uttarakhand. M.Sc. Thesis GBPUAT, Pantnagar.

6. T. Bansal and D. Ganguly (2011)Foil printing process on textile material. Colourage. 58(10): 51.

7. V. Bhandari,A. Rani, M. Gahlot and Sakshi (2019) Aipan: An inspiring folkart for textile designing. Inter $J$ CurrMicrobiol App Sci. 8(6): 527-537.

8. A.I. Devi, and M. Srivastava (2013) Traditional designs of Meitei community of Manipur: adaptation on salwar-kameez. Asian J Home Sci. 8(1): 264-268.

9. A.I. Devi(2011)An exploratory study on traditional textiles and costumes of Manipur and adaptation of its design in saree and salwar kameez. Thesis. M.Sc. MPUAT, Udaipur. 28-30 p.

10. L.J. Devi (2016) Adaptation of textile and architectural designs of Manipur in lifestyle products using transfer printing. Thesis. M. Sc. GBPUA\&T, Pantnagar. 10, 16-111 p.

11. L.J. Devi, A. Rani and M. Gahlot (2019) Designing of kurti using traditional designs of Manipur through transfer printing. Inter J CurrMicrobiol App Sci. 8(8): 267-276.

12. M. Jangwan(2009) Rejuvenate the Kalamkari with heat transfer printing on kurtis. Thesis. M.Sc., BanasthaliVidyapith. 67 p.

13. Y. Joshi (2004) Adaptation of Kumaoni folk designs for block printing. Thesis. M.Sc. GBPUAT, Pantnagar.

14. A. Karolia and R. Prakash (2014)Design and development of fashion accessories inspired from the hand woven shawls of Nagaland. Asian J Home Sci.13(2):416.

15. R. Kaur and I. Gupta (2014)Phulkari and bagh folk art of Punjab: a study of changing designs from traditional to contemporary time. Americ Inter J Res Human, Arts and Soc Sci.5(1):35-43.

16. M. Kaur,S. Bains, S. Grewal, and N. Grewal(2014) Traditional and modern expression of phulkari. Asian $J$ Home Sci. 9(2): 460.

17. S. Keisham(1998) Traditional dress of the Meiteis. Imphal, Bhubon Publishing House. 6-10 p.

18. J.Lantry(2015) Artisan Culture: rethinking sustainability through collaborative exchanges between emerging Australian designers and Indian artisans in fashion and textiles. Thesis. M.Sc., University of Technology, Sydney. iii p. 
19. M. Negi, A. Rani and A. Singh(2015) New horizon for aipan (folk art of Uttarakhand) motifs through appliqué. Inter $J$ Res-Granthaalayah. 3(9): 36-48.

20. M. Negi and A. Rani(2016)New prospects for women empowerment through value addition of remnant fabrics with aipan applique. IndResJ Ext Edn 16(3): 84-88.

21. E.M. Sangma (2011) Adaptation of folk art of Uttarakhand for designing of textiles using weaving technique of Meghalaya. Thesis. M.Sc. GBPUAT, Pantnagar.

22. A. Sharma, S.S.J. Singh and N.M.Rose (2016) Development of motifs: Traditional to contemporary for saris. Res $J$ Recent Sci. 5(7): 44-46.

23. P.G. Tortora (1978) Understanding textiles. Macmillan. 301 to 302,304 to $305 \mathrm{p}$.

24. Vedika, E. Grover, and S. Paul(2014) Adaptation of warli art for development of blocks for printing of apparels. Asian J Home Sci, 9(2): 417. 